patients, FEF 25-75 has been shown to be better correlated with air trapping than $\mathrm{FEV}_{1} \%$, which explains the ability of $\mathrm{FEF}_{25-75}$ to predict response to bronchodilator administration. ${ }^{6}$

Our results support the one airway/one disease hypothesis, ${ }^{1,2,8}$ linking $A R$ and asthma. This is plausible for several reasons. First, genetically, there are common atopic predispositions for AR and asthma. Second, AR and asthma share common pathological aspects; in biopsy studies, there was a high eosinophil count in AR even without asthma, with thickness of the bronchial reticular basement membrane in isolated AR. Third, from the pathogenesis point of view, the systemic release of IL-5 and the stimulation of bone marrow eosinopoiesis after allergen inhalation (challenge test) are important factors involved in the process of global airway allergy. ${ }^{8}$

One limitation of our study is the small numbers. We do not recommend spirometry testing for patients classified as intermittent allergic rhinitis. This could save time and money in primary care, but we do need a larger sample to confirm this finding.

Data from our study raise some additional questions that require further research. First, what is the appropriate cut-off for a clinically relevant reduction in $\mathrm{FEF}_{25-75}$ ? There is a need to reach consensus on interpretation of $\mathrm{FEF}_{25}-75{ }^{3}$ including technical recommendations, the normal cut-off normal values, the methods and reference for a positive reversibility test using FEF25-75, and consensus regarding its utility in practice and its significance as a risk factor for asthma in AR patients. Secondly, can early treatment of $A R$ prevent the onset of asthma? Several pharmacological trials have shown that intranasal inhaled steroids improve asthma control. However, the role in preventing the allergic march from rhinitis to asthma has not been investigated. ${ }^{8}$

\section{Acknowledgments}

We are grateful to Prof. Mounir Osman, the director of the Lattakia hospital, and to Prof. Bassim Dubaybo from Wayne State University for his help in reviewing the manuscript before submission.

\section{Conflicts of interest}

The authors declare that they have no conflicts of interest in relation to this article.

\section{Contributorship}

Dr Yousser Mohammad participated in the study design, writing the manuscript and supervising. Dr Rafea Shaaban participated for the statistical analysis, and the writing of the manuscript. Dr Mustafa Ibrahim participated in the study design and nose examination. Moussa Ismail is a post graduate medical student, he did the data collection and performed plethysmography, and also participated in the drafting of the manuscript.

\section{Funding}

None.

\section{References}

1. Bousquet J, Khaltaev N, Cruz AA, et al. Allergic Rhinitis and its Impact on Asthma (ARIA) 2008 update (in collaboration with the World Health Organization, GA(2)LEN and AllerGen). Allergy 2008;63:Suppl86:8-160. http://dx.doi.org/10.1111/j.1398-9995.2007.01620.x

2. Cruz AA, Popov T, Pawankar R, et al. Common characteristics of upper and lower airways in rhinitis and asthma: ARIA update, in collaboration with GA (2)LEN. Allergy 2007;62:Suppl84:1-41. http://dx.doi.org/10.1111/j.13989995.2007.01551.x

3. Pellegrino R, Viegi G, Brusasco $V$, et al. Interpretative strategies for lung function tests. Eur Respir J 2005;26:948-68. http://dx.doi.org/ 10.1183/09031936.05.00035205

4. French Language Society of Pneumology. Recommandations pour le suivi médical des patients asthmatiques adultes et adolescents. Rev Mal Respir 2005;22:3587-3590

5. McFadden ER, Jr. Resurrection men and the FEF(25-75). J Allergy Clin Immunology 2010;126:535-6. http://dx.doi.org/10.1016/j.jaci.2010.06.035

6. Simon MR, Chinchilli VM, Phillips BR, et al. Forced expiratory flow between $25 \%$ and $75 \%$ of vital capacity and FEV(1)/forced vital capacity ratio in relation to clinical and physiological parameters in asthmatic children with normal FEV(1) values. I Allergy Clin Immunology 2010;126:527. http://dx.doi.org/10.1016/j.jaci.2010.05.016

7. Ciprandi G, Cirillo I, Pistorio A. Impact of allergic rhinitis on asthma: effects on spirometric parameters. Allergy 2008:63:255-60. http://dx.doi.org/10.1111/j.1398-9995.2007.01544.x

8. Braunstahl GJ. United Airways Concept. What Does it Teach Us about Systemic Inflammation in Airways Disease? Proc Am Thorac Soc 2009;6:652-4. http://dx.doi.org/10.1513/pats.200906-052DP

\title{
Knowledge of pulse oximetry among general practitioners in South Australia
}

\author{
*Quirine CA Huijgen ${ }^{\mathrm{a}, \mathrm{b}}$, Tanja W Effinga, Kerry L Hancockc, Tjard R Schermer ${ }^{\mathrm{d}}$, Alan J Crockett \\ a Respiratory Department, Repatriation General Hospital, Adelaide, South Australia \\ b Department of Surgery, Gelre ziekenhuizen, Apeldoorn, The Netherlands \\ c Chandlers Hill Surgery, Adelaide, South Australia \\ d Radboud University Nijmegen Medical Centre - Primary and Community Care, Nijmegen, The Netherlands \\ e Primary Care Respiratory Research Unit, The University of Adelaide, School of Population Health \& Clinical Practice, Adelaide, \\ South Australia
}

\footnotetext{
*Correspondence: Miss Quirine Huijgen, Department of Surgery, Gelre Ziekenhuizen, Albert Schweitzerlaan 31, Apeldoorn, the Netherlands Tel: 0031641166403 E-mail: quirine_h@hotmail.com

Received 8th August 2011; accepted 14th August 2011; online 24th October 2011

(C) 2011 Primary Care Respiratory Society UK. All rights reserved http://dx.doi.org/10.4104/pcrj.2011.00088
}

\section{Dear Sirs,}

Pulse oximetry is a non-invasive, reliable technology for measuring arterial oxygen saturation (SpO2). ${ }^{1}$ Pulse oximeters are part of standard care and it is hard to imagine emergency departments, intensive care units and general hospital wards without them. Recently, portable, user-friendly and relatively nonexpensive pulse oximeters have become available, making them 
Table 1. Associations between knowledge score and different descriptive variables

\begin{tabular}{|c|c|c|c|}
\hline Variable & $\begin{array}{l}\mathrm{N}=46 \\
\text { Frequency } \\
\mathrm{n} \quad(\%)\end{array}$ & $\begin{array}{l}\text { Mean score \% } \\
\text { (SD and range) }\end{array}$ & $p$-value \\
\hline $\begin{array}{l}\text { Number of years of experience as GP* } \\
\text { - } \quad 1 \text { year } \\
\text { - } 1-5 \text { years } \\
\text { - } 6-10 \text { years } \\
\text { - }>10 \text { years }\end{array}$ & $\begin{array}{ll}3 & (6.5) \\
8 & (17.4) \\
5 & (10.9) \\
29 & (63.0)\end{array}$ & $\begin{array}{ll}53.3 & (5.9 ; 48.6-60.0) \\
45.7 & (16.2 ; 22.9-68.6) \\
33.1 & (20.2 ; 8.6-62.9) \\
30.2 & (19.2 ; 0.0-68.6)\end{array}$ & $0.03^{\dagger \neq}$ \\
\hline $\begin{array}{l}\text { Experience with the pulse oximeter } \\
\text { - Yes } \\
\text { - No }\end{array}$ & $\begin{array}{ll}35 & (76.1) \\
11 & (23.9)\end{array}$ & $\begin{array}{l}39.5(17.0 ; 8.6-68.6) \\
20.8(19.3 ; 0.0-57.1)\end{array}$ & $0.006 \S$ \\
\hline $\begin{array}{l}\text { Number of years of experience with pulse oximetry } 19 \\
\text { - } \quad 1 \text { year } \\
\text { - } 1-5 \text { years } \\
\text { - } 6-10 \text { years } \\
\text { - }>10 \text { years }\end{array}$ & $\begin{array}{ll}2 & (5.7) \\
16 & (45.7) \\
4 & (11.4) \\
11 & (31.4) \\
\end{array}$ & $\begin{array}{ll}25.7 & (4.0 ; 22.9-28.6) \\
42.9 & (15.9 ; 17.1-68.6) \\
35.0 & (2.9 ; 31.4-40.0) \\
42.1 & (21.4 ; 8.6-68.6) \\
\end{array}$ & $0.9^{\dagger}$ \\
\hline $\begin{array}{l}\text { In possession of pulse oximeter* } \\
\text { - Yes } \\
\text { - No }\end{array}$ & $\begin{array}{ll}28 & (60.9) \\
17 & (37.0) \\
\end{array}$ & $\begin{array}{ll}38.5 & (17.7 ; 8.6-68.6) \\
29.7 & (21.2 ; 0.0-68.6) \\
\end{array}$ & $0.17 \S$ \\
\hline $\begin{array}{l}\text { Use of pulse oximeter per week }+ \text { ף } \\
\text { - I don't use it } \\
\text { - } 1-6 \text { times a week } \\
\text { - 7-10 times a week } \\
\text { - }>10 \text { times a week } \\
\text { - Other \# }\end{array}$ & $\begin{array}{ll}10 & (28.6) \\
9 & (25.7) \\
3 & (8.6) \\
3 & (8.6) \\
8 & (22.9)\end{array}$ & $\begin{array}{ll}39.7 & (15.6 ; 17.1-68.6) \\
38.1 & (20.3 ; 8.6-68.6) \\
26.7 & (4.4 ; 22.9-31.4) \\
53.3 & (21.6 ; 28.6-68.6) \\
42.9 & (15.6 ; 22.9-60.0)\end{array}$ & $0.97^{\dagger}$ \\
\hline
\end{tabular}

SD: standard deviation. N/A not applicable.

* 1 missing; † One-way ANOVA; $\neq$ To obtain subgroups of equal size, the categories were redefined into 0-5 years of experience ( $p=0.009), 6-10$ years of experience $(p=0.733)$ and more than 10 years of experience in general practice $(p=0.744)$; $\S$ Mann Whitney U test; 1 Only GPs with experience with pulse oximetry (n=35); \# 3 Gps used the pulse oximeter less than weekly, 5 GPs used the pulse oximetry when working in the hospital

much more accessible for general practitioners (GPs). Pulse oximetry appears to have a wide range of indications in the primary care setting. ${ }^{2}$ COPD guidelines suggest that oxygen saturation measurements should be performed to aid GPs in effective patient management.

In order to interpret measurements, knowledge is required of pulse oximetry technology, respiratory anatomy and physiology, and the oxyhaemoglobin dissociation curve.,4 The latter explains the relationship between arterial oxygen saturation and partial pressure of arterial oxygen. Pulse oximetry does not provide information about the haemoglobin level, the adequacy of ventilation, nor the efficiency of oxygen delivery to the tissues. ${ }^{5}$ Also, pulse oximeters can give inaccurate information when used on polished nails, with bright overhead lights and in low perfusion states. ${ }^{4,6}$ It is essential to be aware of these limitations. Research in different hospital settings has shown that clinicians' understanding of pulse oximetry is rather limited.

As far as we are aware, no previous research has been conducted of GPs' knowledge of pulse oximetry. Therefore, the aim of this cross-sectional questionnaire study was to gain insight into the current knowledge, interpretative skills and attitudes of South-Australian GPs regarding pulse oximetry.

We approached all GP networks in the Adelaide area to recruit participants. An internet-based questionnaire was used to assess interpretative skills, attitudes, and knowledge regarding pulse oximetry (when and how to use the device; normal range of oxygen saturation; accuracy; oxyhaemoglobin dissociation curve; limitations of the pulse oximetry device). The questionnaire (available online at www.thepcrj.org) was based on questionnaires used in previously reported surveys. ${ }^{7-10} \mathrm{~A}$ maximum of 35 points could be obtained. Scores were converted to percentages (0-100\%). Data were collected in November 2010. Descriptive characteristics were used to describe the different variables. Associations between total knowledge score and descriptive variables were analysed using the Mann-Whitney $U$ test and one-way ANOVA combined with multiple regression analyses (SPSS version 17.0).

A total of 46 questionnaires were returned from 42 GPs $(91.3 \%)$ and 4 GP registrars (8.7\%). The majority of participants (76.1\%) had experience with pulse oximetry and a pulse oximeter was owned by $60.9 \%$ of the participants. Most participants $(58.7 \%$ ) believed they had not received adequate training in the use of pulse oximetry. The mean test score was $35.0 \%(19.1 \% \mathrm{SD})$ and ranged from $0 \%$ to $68.6 \%$. Half of the participants did not know that a pulse oximeter measures the percentage of oxygenated haemoglobin and only $45.7 \%$ knew that the normal oxygen saturation range for an adult is 96 to $99 \%$. Overall, only $31.2 \%$ of the questions about the limitations were answered correctly. Only one GP answered all three questions about the oxyhaemoglobin dissociation curve correctly and $45.7 \%$ answered all three questions incorrectly.

Experience with pulse oximetry resulted in a significantly higher score $(p<0.01)$. Years of experience in general practice was overall significantly negatively associated with the knowledge test score (Table 1).

Although the group of GP registrars was very small, a 
significant difference in test scores was found between GP registrars and GPs (53.6\% versus 33.3\%, $p=0.046$ ).

This study, albeit small, confirmed our hypothesis that knowledge of pulse oximetry among GPs is relatively poor across all aspects of pulse oximetry. Whereas years of experience in general practice had a negative correlation with knowledge, experience with the pulse oximeter correlated positively with knowledge. To our knowledge this is the first study about pulse oximetry knowledge performed in a primary care setting. Our questionnaire is not identical to those used in other studies, but when we compare our results to earlier studies performed in hospital settings, the overall score seems low. ${ }^{5}$

The response rate on the internet survey was very low, with only $1.6 \%$ of all invited GPs completing the internet-based questionnaire - a significant limitation of this study. However, although the study population was small, we believe it to be a representative sample of GPs in Australia.

Before pulse oximetry can be more widely implemented in primary care, knowledge about its technology, limitations and the principles behind the oxyhaemoglobin dissociation curve should be improved. Therefore, appropriate training of GPs and registrars is essential.

\section{Conflicts of interest}

The authors declare that they have no conflicts of interest in relation to this article.

\section{Contributorship}

QH: study preparation and execution, analyses, paper writing; TE: study preparation, analyses, paper writing; KH: study preparation, study logistics, paper writing; TS: initiator of study, paper writing; AC: initiator of study, paper writing.

\section{Funding}

None.

\section{References}

1. Anzueto A, Casaburi R, Holmes S, Schermer T. Clinical use of pulse oximetry, pocket reference 2010. http://www.theipcrg.org/resources/oximetry pocket_guide.pdf

2. Schermer $\mathrm{T}$, Leenders $\mathrm{J}$, in 't Veen $\mathrm{H}$, et al. Pulse oximetry in family practice: indications and clinical observations in patients with COPD. Fam Pract 2009;26(6):524-31. http://dx.doi.org/10.1093/fampra/cmp063

3. Elliott M, Tate R, Page K. Do clinicians know how to use pulse oximetry? A literature review and clinical implications. Aust Crit Care 2006;19(4):139-44. http://dx.doi.org/10.1016/S1036-7314(06)80027-5

4. Holmes S, Peffers S, Mallet S. PCRS-UK Opinion Sheet No. 28: Pulse Oximetry in Primary Care. www.pcrs-uk.org. 2009.

5. Grap MJ. Pulse oximetry. Crit Care Nurse 1998;18(1):94-9

6. Amar D, Neidzwski J, Wald A, Finck AD. Fluorescent light interferes with pulse oximetry. J Clin Monit 1989;5(2):135-6. http://dx.doi.org/10.1007/BF01617888

7 Rodriguez LR, Kotin N, Lowenthal D, Kattan M. A study of pediatric house staff's knowledge of pulse oximetry. Pediatrics 1994;93(5):810-13.

8. Attin $\mathrm{M}, \mathrm{Cardin} \mathrm{S}$, Dee $\mathrm{V}$, et al. An educational project to improve knowledge related to pulse oximetry. Am J Crit Care 2002;11(6):529-34.

9. Stoneham MD, Saville GM, Wilson IH. Knowledge about pulse oximetry among medical and nursing staff. Lancet 1994;344(8933):1339-42. http://dx.doi.org/10.1016/S0140-6736(94)90697-1

10. Popovich DM, Richiuso N, Danek G. Pediatric health care providers' knowledge of pulse oximetry. Pediatr Nurs 2004;30(1):14-20.

See online Appendix 2 at www.thepcrj.org for online-only supplement

Available online at http://www.thepcrj.org 


\section{Asthma Indicators Pilot Study}

Primary Care Asthma Performance Indicators (PC-API)
Site ID:

Person who filled out this form:

Patient Visit Date:

Visit Type:
Patient's Demographic Data:

Sex: Male $\bigcirc$ Female

Year of birth (yyyy):

First 3 Digits in Postal Code(e.g. M5G __ ):

\section{Asthma Indicators}

1. PFT

2. Medication Use

a) Patient is using inhaled corticosteroids (ICS)

b) In last 12 months, patient's self-reported number of ICS prescription filled

c) In last 4 weeks, patient's self-reported number of short-acting B2-agonist (2 puffs) per week

d) In last 4 weeks, patient's self-reported number of B2-agonist-free days

e) Patient has demonstrated their inhaler technique regularly

3. Asthma Control

a) In last 6 months, patient's asthma symptoms control were assessed

b) In last 4 weeks, patient's asthma is well-controlled

c) In last 4 weeks, patient's self-reported symptom-free days

d) In last 12 months, patient's self-reported days missed from school or work due to asthma

4. Exacerbations

In last 12 months, patient has more than 1 asthma exacerbation

5. Health Care Use

a) In last 12 months, number of ED visits for asthma

b) In last 12 months, number of urgent care visits for asthma

c) In last 12 months, number of primary care visits for asthma

d) Patient has a routine health care provider

6. Action Plan

7. Asthma Education

8. Smoking Cessation

9. Quality of Life
Patient has received a written asthma action plan

Referred to see a certified asthma educator

Patient has received advice to stop smoking

CYes $\bigcirc$ No

Patient's assessment of quality of life

( 5 point scale: $1=$ excellent, $2=$ very good, $3=$ good, $4=$ fair, $5=$ =poor)
CYes $\bigcirc$ No

CYes $\bigcirc$ No

Yes $O$ No

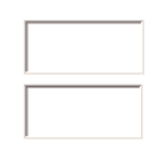$$
\text { Yes } \bigcirc \text { No }
$$

Yes $\bigcirc$ No

Yes $\bigcirc$ No

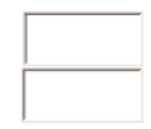

CYes $\bigcirc$ No

\section{Thank you for filling out this form.}

To submit please click on the appropriate button.

Submit by Email

\section{Print Form}




\section{Knowledge about pulse oximetry among GPs}

The new Royal Australian College of General Practitioners Standards for general practices highlight the pulse oximeter as 'diseretionary'. While knowledge about this tool is required for correct interpretation of results, few GPs have received formal training. The aim of this study is to investigate GPs knowledge about pulse oximetry.

Please answer the following questions as accurately as possible. All questionnaires will be processed anonymously.

\section{Demographic and descriptive characteristics (Please circle the answer which is applicable)}

1. What is your age? years old

2. What is your gender? Male/Female

3. Are you a:
a. VR/ non-VR General Practitioner
b. GP registrar
c. Other. please specify.

4. On average, how many sessions a week do you work?
a. $\leq 2$
b. $2-5$
c. $6-8$
d. $8-10$
e. $\geq 11$
f. Other, please specify

5. What type of practice do you work in?

a. Solo GP practice (or equivalent of 1 full time GP)

b. Small group practice ( $\leq 4$ full time equivalent GPs)

c. Large group practice (5-7 full time equivalent GPs)

d. Very large group practice $(\geq 8$ full time equivalent GPs)

c. Other. please specify

6. Where is your practice situated?
a. Inner metropolitan
b. Outer metropolitan
c. Rural
d. Remote
c. Other, please specify

7. Number of years of patient related experience in general practice?
a. $<6$ months
b. 6-12 months
c. 1-5 years
d. 6-10 years
e. $>10$ years

8. Are you specialised in respiratory diseases or are you a member of a committee for respiratory diseases?
a. Yes
b. No
c. Other, please specify

9. Have you had any clinical experience in using pulse oximetry?

a. No $\rightarrow$ skip question $10,14,15$ and 16

b. Yes (if yes, please indicate all that apply)

cc. In a hospital setting

dd. In a general practice setting

ee. Other, please specify 
10. How many years of experience have you had using pulse oximeters?
a $<6$ months
b. 6-12months
c. 1-5 years
d. 6-10 years
c. >10years
f. Other, please specify

11. Does your practice have a pulse oximeter?
a. Yes (skip question 17)
b. No (skip question 12 and 13)

12. When was it purchased?
a. $<1$ year ago
b. 1-2 years ago
c. 2-5 years ago
d. $>5$ years ago
e. I don I know

13. How often do you estimate it is being used across the whole practice?
a. Daily
b. Weekly
c. Monthly
d. Rarely
e. Other, please specify

14. How often do you use the pulse oximeter in your practice?
a. I don't use it ( skip question $15+16$ )
b. 1-3 times a week
c. 4-6 times a week
d. 7-10 times a week
e. > 10 times a week
f. I use pulse oximetry elsewhere, specify where and how often:

15. In which of the situations do you use the pulse oximeter?

\begin{tabular}{|l|c|}
\hline To obtain an objective measurement in patients with acute or worsening dyspnoca & Yes/No \\
\hline Assessing severity of COPD exacerbations & Yes/No \\
\hline Rule out acute respiratory failure or low oxygenation & Yes/No \\
\hline Assessing severity of lower airway disease & Yes/No \\
\hline Differentiation between hyperventilation and cardiopulmonary disorders & Yes/No \\
\hline To obtain an objective measurement in patients with COPD with suspected respiratory insufficiency & Yes/No \\
\hline Determination of a baseline/comparator value in patients with COPD or asthma & Yes/No \\
\hline Monitoring the course or recovery after respiratory failure & Yes/No \\
\hline Monitoring the course or recovery of dyspnoea in patients with COPD or asthma & Yes/No \\
\hline To assist in determining starting or continuing oxygen therapy in patients with terminal discase & Yes/No \\
\hline Other, please specify: & \\
\hline
\end{tabular}

16. How often do you document the reading from the pulse oximeter in the clinical record?
a. Every time
b. Most of the times
c. Sometimes
d. Never

17. Are you or your practice considering purchasing a pulse oximeter in the next 12 months?
a. No
b. Yes, regardless of practice accreditation requirements
c. Yes, only if it becomes a required piece of equipment for practice accreditation

18. Do you feel you have received adequate training in the use of pulse oximeters?
a. Yes
b. No 


\section{Appendix 2 - Huijgen et al.}

19. What kind of training have you had in the use of pulse oximeters? (Circle all that apply)
a. No training
b. Formal lecture
c. Self study
d. Informal training during clinical practice
e. In-service by equipment supplier
f. Equipment manual
g. Other, please specify.

Pulse oximetry knowledge questions (please circle the answer which is applicable)

1. What does the pulse oximeter measure?
a. The pereentage of haemoglobin which is oxygenated (oxyhaemoglobin)
b. The percentage of body surface area which is adequately oxy genated
c. $\mathrm{PaO} 2$ (partial pressure of oxygen)
d. PtcO2 (transcutaneous partial pressure of oxygen)
e. I don't know

2. Normal saturation for a 2-year-old is best described in which one of the following ranges:
a. $85-90 \%$
b. $90-95 \%$
c. $93-97 \%$
d. $97-99 \%$
c. $98-100 \%$
f. I don't know

3. Normal saturation for an adult is best described in which one of the following ranges:
a. $85-90 \%$
b. $90-95 \%$
c. $93-97 \%$
d. $96-99 \%$
c. $97-100 \%$
f. I don 1 know

4. Pulse oximeter readings are least accurate at which of the following saturations?
a. $95-100 \%$
b. $85-95 \%$
c. $70-85 \%$
d. $<70 \%$
c. I don't know

5. Patient A's oximeter reading has fallen from $95 \%$ to $90 \%$. Patient B's oximeter reading has fallen from $80 \%$ to $75 \%$. Assuming the clinical and laboratory parameters are the same between the two patients, which of the following is correct
a. Patient $A$ had a change in partial pressure of oxygen that is fourfold greater than patient $B$
b. Patient $A$ and $B$ had equal changes in partial pressure of oxygen
c. Patient B had a change in partial pressure of oxygen that is fourfold greater than patient $A$
d. These changes are within the error of the method
e. I don't know

6. An oxygen saturation of $90 \%$, under normal metabolic conditions, will correspond to partial pressure of oxygen ( $\mathrm{PaO} 2)$ of approximately:
a. $90 \mathrm{mmHg}$
b. $85 \mathrm{mmHg}$
c. $75 \mathrm{mmHg}$.
d. $60 \mathrm{mmHg}$
c. $50 \mathrm{mmHg}$.
f. I don't know 


\section{Appendix 2 - Huijgen et al.}

7. A 1-month-old infant is in $30 \%$ oxygen with an $\mathrm{O} 2$ saturation of $99 \%$. The $\mathrm{PaO} 2$ is:

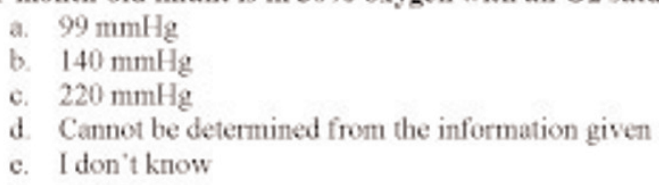

8. Identify what effect, if any, the following factors have on the pulse oximetry reading? (please tick one box per item)

\begin{tabular}{|l|l|l|l|l|l|}
\hline & No effect & $\begin{array}{l}\text { Falsely } \\
\text { decrease }\end{array}$ & $\begin{array}{l}\text { Falsely } \\
\text { increase }\end{array}$ & $\begin{array}{l}\text { May not be able to pick up } \\
\text { signal }\end{array}$ & $\begin{array}{l}\text { I don't } \\
\text { know }\end{array}$ \\
\hline Nail polish & & & & & \\
\hline $\begin{array}{l}\text { Carbonmonoxide } \\
\text { poisoning }\end{array}$ & & & & & \\
\hline Jaundice & & & & \\
\hline Shivering & & & & \\
\hline $\begin{array}{l}\text { Dark skinned } \\
\text { race }\end{array}$ & & & & & \\
\hline $\begin{array}{l}\text { Peripheral } \\
\text { vasoconstriction }\end{array}$ & & & & & \\
\hline Hypertension & & & & & \\
\hline Tremor & & & & & \\
\hline $\begin{array}{l}\text { Cardiac } \\
\text { arthythmias }\end{array}$ & & & & & \\
\hline Shock & & & & & \\
\hline Hypotension & & & & & \\
\hline Hypothermia & & & & & \\
\hline Anaemia & & & & & \\
\hline Movement & & & & & \\
\hline $\begin{array}{l}\text { Bright overthead } \\
\text { lights }\end{array}$ & & & & & \\
\hline
\end{tabular}

9. An $\mathrm{SpO}_{2}$ of $92 \%$ or less (at sea level) suggests hypoxemia

10. Pulse oximetry is a method for continuous non-invasive measurement of adequacy of ventilation

11. Clinical observation alone is as effective as pulse oximetry monitoring in the rapid detection of hyposemia

12. Pulse oximetry sensors can be placed at the same extremity as the non-invasive blood pressure monitoring device

13. Spot checks of pulse oximetry readings are as helpful in assessing a patients oxygenation status as evaluation of continuous monitoring over time

14. Oxygen saturation monitoring could replace arterial blood gases when monitoring ventilation abnormalities

15. In older children who are receiving inot ropes, vasopressors, vasodilators, sedatives, or analgesics, changes in oxygenation are more accurately detected by pulse oximetry than by any other non-invasive method

16. During vasoconstriction and hypotension, the overall performance of finger sensors is generally better than performance of sensors at other sites (ie, ear, forehead, nose)

17. If a patient is breathing normal air, $100 \%$ saturation can be achieved

18. In a patient with a pulse oximeter reading of $92 \%$, the true saturation value could be $90 \%$

19. If an anaemic patient has a normal satu ration value, he could still be hypoxic

20. Body temperature should be taken in account, when you are using the pulse oximeter

21. The pulse oximeter measures the absorption of electrical waves by haemoglobin
Truefalse/ 1 don't know

True/false/ I don't know

Trueftalse/ I don't know

Trueffalse/ I don't know

Truefialse/ I don't know

Trueftalse/ I don't know

True/false' I don't know

True/false/ 1 don't know

True/false/I don't know

Trueftalse' I don't know

Trueftalse' I don't know

True/false/ don't know

True/false/ don't know

\section{Thank you for your participation!}

